East African Medical Journal Vol. 77 No. 10 October 2000

PATTERN AND EXPERIENCE WITH CANCERS TREATED WITH THE CHINESE GWGP80 COBALT UNIT AT MULAGO HOSPITAL, KAMPALA

J. B. Kigula Mugambe, MBChB, MMed (Rad) MUK, MSc (Rad. Oncol.) Cairo, Department of Radiology, Makerere University Medical School, P.O. Box 7051, Kampala

- Uganda and P. Wegoye, DCR(R) London, Dip. Med. Eng. (Swaziland), Department of Radiotherapy, Mulago Hospital, P.O. Box 7051, Kampala, Uganda.

Request for reprints to: Dr. J. B. Kigula Mugambe, Department of Radiology, Makerere University Medical School, P.O. Box 7051, Kampala, Uganda.

\title{
PATTERN AND EXPERIENCE WITH CANCERS TREATED WITH THE CHINESE GWGP80 COBALT UNIT AT MULAGO HOSPITAL, KAMPALA
}

\author{
J. B. KIGULA MUGAMBE and P. WEGOYE
}

\begin{abstract}
Objectives: To review the pattern of cancers treated at Mulago hospital with the new Chinese GWGP80 Cobalt - 60 unit and to analyse its breakdowns, downtime and attempts at repairs during its first two years of operation and to assess its reliability and safety.

Design: A retrospective cross - sectional study.

Data source: This involved analysing data from the radiotherapy records book, the patient's case notes and a "fault's Log book" which was opened on the day the machine was commissioned. All causes of non - performance were documented in this book and an assessment of the severity of breakdowns, period of downtime and repairs carried out was done. Faults requiring only a few minutes maintenance work or non-performance due to general power failure were however excluded. All patients who had been treated earlier on the orthovoltage machine and were re-treated on the cobalt unit were also excluded from the analysis.

Setting: Department of Radiotherapy, Mulago Hospital, Kampala, Uganda.

Results: One thousand and forty eight new patients were treated during this period. Three hundred and fifty nine were males and 689 were females. Cancer of the cervix was by far the commonest cancer seen $(\mathbf{3 7 . 2 \%})$ followed by head and neck cancers $(\mathbf{1 6 . 0 \%})$, breast cancers (13.8\%) and Kaposi's sarcoma (10.5\%). There were 47 machine faults. Most of these were relatively minor requiring only a few hours of maintenance work. Two of these faults were however major with downtime of more than a week. These were due to a failure of the "force back system" of the radioactive source necessitating it to be hammered back into the safe position.

Conclusion: The Chinese GWGP80 Cobalt unit has effectively treated a large number of cancer patients but the failures of the "force back system" of its radioactive source compromise its radiation safety and ideally would require a change in the engineering design to decrease on the associated radiation hazards.
\end{abstract}

\section{INTRODUCTION}

Through a project of the International Atomic Energy Agency (IAEA), Uganda was supplied with a Chinese GWGP 80 Cobalt 60 Teletherapy unit which was installed in the radiotherapy department of Mulago Hospital which is Uganda's national referral and teaching hospital.

It was commissioned in May 1995 and began working on 1st June 1995(1). A retrospective study was done involving analysis of the radiotherapy record's book and patients' case notes to indicate the pattern of disease as seen in the department of radiotherapy from June 1995 up to 31st July 1997.

A review of all documented machine faults, downtime and repairs of the machine was also done for the same period. This report is expected to highlight the availability of the radiation therapy services, the pattern of tumours treated and the reliability and safety of the new treatment unit. This would hopefully assist in strengthening the radiotherapy services in the country and give some information to other users who may be interested in a similar machine.

\section{MATERIALS AND METHODS}

This was a retrospective cross-sectional descriptive study. The general objectives were to find out the pattern of cancers treated with the new Chinese GWGP80 cobalt-unit and to report on the breakdowns, downtime and repairs of this machine during the same period.

This review covered a period from 1st June, 1995 to 31st July, 1997. The machine was however not functional for two of these months due to a pilferage of the control panel and TV monitor leaving an effective, operational period of only 24 months.

During the period all causes of non-performance which required the intervention of a maintenance person were meticulously documented with regards to breakdowns, downtime and all the repairs done. The times where general power failure led to non-functioning of the machine were not included except those cases where only one of the three phases was off. These cases were not readily obvious and still required the maintenance 
person to verify the situation. Conditions requiring only a few minutes of maintenance work were also excluded from the study.

All patients who had been treated earlier on the orthovoltage machine and were re-treated on the cobalt unit were reported but were not further analysed.

\section{RESULTS}

A total of 1292 patients were treated on this machine during this period. Two hundred and forty four were old patients who had been treated earlier on the orthovoltage machine and were re-treated on the cobalt machine during this period. These were not further analysed. One thousand and forty eight were new patients, of which 359 were males and 689 were females. The male to female ratio was 1: 1.9. The age range was from one year to 89 years. Figure 1 shows the age and sex distribution of these patients.

\section{Figure 1}

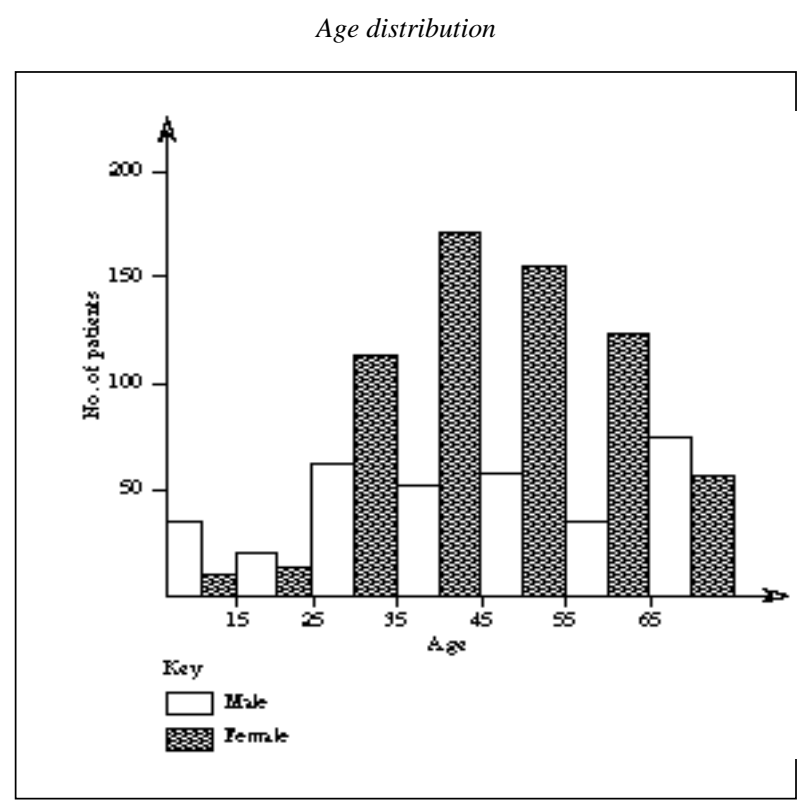

Table 1

Frequency distribution of various tumours treated by radiotherapy

\begin{tabular}{lrrrr}
\hline Site & Male & Female & Total & $\%$ \\
\hline Cervix & & & & \\
Head and neck & 125 & 390 & 390 & 37.2 \\
Breast & 2 & 63 & 188 & 17.9 \\
Kaposi's sarcoma & 80 & 143 & 145 & 13.8 \\
Soft tissues & 19 & 30 & 110 & 10.5 \\
UKP & 20 & 12 & 31 & 3.0 \\
Oesophagus & 14 & 4 & 24 & 2.3 \\
Penis & 19 & 6 & 20 & 1.9 \\
Prostate & 16 & - & 19 & 1.8 \\
Skin & 11 & - & 16 & 1.5 \\
Lung & 6 & 3 & 14 & 1.3 \\
Colorectal & 9 & 7 & 13 & 1.2 \\
NHL & 10 & 4 & 13 & 1.2 \\
Brain & 9 & 3 & 13 & 1.2 \\
Others & 19 & 1 & 10 & 1.0 \\
\hline
\end{tabular}

UKP refers to tumours of unknown primary

NHL refers to non-Hodgkin's lymphoma and "others" refers to a long list of more rare tumour sites including testis, bladder and kidney.
Table 2

Frequency distribution of the head and neck tumours

\begin{tabular}{lrrrr}
\hline Tumour site & Male & Female & Total & $\%$ \\
\hline Nasopharynx & 41 & 14 & 55 & 29.2 \\
Eye & 14 & 11 & 25 & 13.3 \\
Mouth & 12 & 11 & 23 & 12.2 \\
Salivary gland & 11 & 9 & 20 & 10.6 \\
Maxillary antrum & 15 & 4 & 19 & 10.1 \\
Larynx & 14 & 2 & 16 & 8.5 \\
Nose & 4 & 3 & 7 & 3.7 \\
Tonsil & 5 & 2 & 7 & 3.7 \\
Tongue & 2 & 4 & 6 & 3.2 \\
Thyroid & 3 & 2 & 5 & 2.7 \\
Hypopharynx & 3 & 0 & 3 & 1.6 \\
Lip & 1 & 1 & 2 & 1.1 \\
\hline
\end{tabular}

Table 3

Classification of breakdowns according to downtime

\begin{tabular}{llcc}
\hline Category & Period of downtime & Frequency & Percentage \\
\hline I & $1-2$ hours & 23 & 48.9 \\
II & $3-24$ hours & 8 & 17.0 \\
III & $2-3$ days & 12 & 25.5 \\
IV & 4-7 days & 2 & 4.3 \\
V & more than one week & 2 & 4.3 \\
\hline
\end{tabular}

Table 4

Frequency of the different machine faults

\begin{tabular}{lcr}
\hline Fault & Frequency & $\%$ \\
\hline "One phase off" type of power failure & 16 & 34.0 \\
No gantry / couch movement & 11 & 23.4 \\
Y collimator stuck & 4 & 8.5 \\
Routine service & 3 & 6.4 \\
"Beam on" indicator Lamp off & 2 & 43 \\
SSD light fuses blown & 2 & 4.3 \\
Source stuck & 2 & 4.3 \\
Light beam Lamp off & 2 & 4.3 \\
Control panel readjustment & 1 & 2.1 \\
Magnetic reel switch off & 1 & 2.1 \\
Video cameras off & 1 & 2.1 \\
Compressor motor blown & 1 & 2.1 \\
Pneumatic IC faulty & 1 & 2.1 \\
\end{tabular}

Table 2 shows the frequency distribution of the common tumours of the head and neck tumours. A total of 47 faults were documented during the same period. Table 3 shows the severity of breakdowns according to the downtime. Table 4 shows the frequency of the different machine faults.

\section{DISCUSSION}

Carcinoma of the uterine cervix was the most common tumour treated by radiotherapy during this time. It accounted for $37.2 \%$ of all cancers treated in the unit. This was followed by head and neck tumours constituting $17.9 \%$ of all tumours. These tumours were classified together as one site because of the unique treatment 
features and precautionary measures required for their effective management. Table 2 however showed a breakdown of these head and neck tumours. Nasopharyngeal tumours constituted $29.2 \%$ of the head and neck tumours and about $5 \%$ of all the tumours seen.

A high male to female ratio of 2.9:1 was shown in this series which has been reported elsewhere(2). Eye tumours constituted about $13.3 \%$ of all head and neck tumours (Table 2). An interesting fact was that 13 of these 25 eye tumours were of retinoblastoma and they all occurred in children of five years and below. Other tumours which showed high male to female ratios in this series included brain 9:1, larynx 7:1, maxillary antrum $3.75: 1$, skin $3.67: 1$, Kaposi's sarcoma 2.67:1, oesophagus 2.33:1 and colorectal tumours 2.25:1. No clear explanation can be given for these high ratios although some have been reported in other series(3).

Although smoking and consumption of alcoholic beverage may be higher in males and could be factors in the causation of tumours of the respiratory system and upper digestive system, the male to female ratio for lung cancer was only 1.1:1. The female to male ratio of breast cancer has been reported to be 100:1 in the Western literature. A lower ratio of 73.5:1 has however been reported in Ugandan Africans(4) which agrees with our figure of 71.5:1.

Although, Wabinga reported Kaposi's sarcoma (KS) as the commonest cancer in Uganda, it accounted for only $10.5 \%$ of the cancers seen in this study(5). This is not at all surprising because only patients with localised KS are referred for radiotherapy. The rest of the patients with more generalised KS (which is common in the epidemic KS) are treated with chemotherapy. Indeed some of these patients with AIDS may never receive any treatment for the $\mathrm{KS}$ as it may be just an incidental finding with the patient presenting with other more severe and life threatening conditions.

Table 3 shows that most of the documented machine failures were minor with a downtime of less than one day ( $65.9 \%$ ). Table 4 shows that 16 of the documented 47 failures were due to power problems where one of the three phases supplying the machine would go off. The actual machine failures were therefore only thirty one. Most of these faults were relatively minor necessitating cleaning or replacing control switches and fuses or replacing indicator lamps. The closed circuit Video Camera supplied with the equipment failed after one year and was replaced by a new Phillips camera.

Two of the documented 31 faults were however major. The "force back system" of the radioactive source failed while the machine was in the treatment position and the radioactive source had to be hammered back into the safe position. As result there was increased radiation exposure to the maintenance technician although the actual dose received by the technician was well within the maximum permissible dose.

In each of these occasions, the breakdown lasted about two weeks. The first time the problem was due to a blown motor for the compressor of the pneumatic system (which creates a vacuum to suck back the radioactive source). The second time the fault was due to a worn-out piston ring making creation of the above vacuum impossible. That piston ring could not be obtained locally and an oil seal from a car engine was improvised as a replacement which has been working quite effectively.

For all the documented faults, an experienced maintenance technician was able to quickly identify the problem. The longer breakdown times were due to lack of spare parts making it impossible for him to rectify the problem.

\section{CONCLUSIONS}

(i) The high frequency of cancer of the cervix should be taken into consideration in the development of a cancer control programme for Uganda with a special emphasis on its prevention, early diagnosis and effective treatment.

(ii) Larger studies of the pattern of cancers in Uganda may help in explaining the interesting sex distribution reported in this study.

(iii) The Chinese GWGP80 COBALT 60 machine has proved quite reliable with only a few breakdowns in a two year period. The failures of the source return system are however serious and would ideally require a change in the design to improve on radiation safety.

Availability of a set of spare parts like switches for the hand control unit, drive belts, fuses for the indicator lamps etc. would significantly minimise the downtime.

\section{REFERENCES}

1. Kigula Mugambe J.B, Durosinmi- Etti F.A. Radiotherapy in cancer management at Mulago Hospital, Kampala - Uganda. East Afr. Med. J. 1996; 73: 611-613.

2. Fraumeni F., Hoover R.N., Devesa S.S. and Kinlen L.J. in Cancer: Principles and Practice of Oncology; edited by Devita Vincent et al 3rd edition 1989; J.B. Lippincott Company, Philadelphia. Page 200-225.

3. Nzarubara R.G. in Surgery in the Community (breast cancer); Makerere University Press, Kampala 1990; 187-193.

4. Wabinga H.R., Parkin D.M., Wabwire - Mangeni F.Q. and Mugerwa J.W. Cancer in Kampala, Uganda in 1989-91, Changes in the era of AIDS. Int. J. Cancer: 1993; 54:26-36. 